Indonesian Journal of Electronics and Instrumentation Systems (IJEIS)

Vol.10, No.2, October 2020, pp. 109 120

ISSN (print): 2088-3714, ISSN (online): 2460-7681

DOI: https://doi.org/10.22146/ijeis.36492

\title{
Rancang Bangun Platform Intel Edison Sebagai IoT Gateway Berbasis Protokol MQTT
}

\author{
Anggit Wicaksana ${ }^{* 1}$, Bakhtiar Alldino Ardi Sumbodo ${ }^{2}$ \\ ${ }^{1}$ Program Studi Elektronika dan Instrumentasi, FMIPA UGM, Yogyakarta, Indonesia \\ ${ }^{2}$ Departemen Ilmu Komputer dan Elektronika, FMIPA UGM, Yogyakarta, Indonesia \\ e-mail: *1anggitw@outlook.com, ${ }^{2}$ b.alldino.as@ugm.ac.id
}

\begin{abstract}
Abstrak
Peran IoT gateway vital dalam jaringan IoT, seperti misalnya untuk menguatkan manajemen sensor. Untuk itu, pada penelitian ini dirancang sebuah IoT gateway berbasis protokol MQTT yang diimplementasikan pada platform Intel Edison. Digunakan sepuluh buah node sensor dengan menggunakan topologi star.

Hasil dari penelitian ini berupa sebuah sistem IoT gateway yang mampu menerima paket data dari node sensor, menyimpannya di basis data sekaligus publish data tersebut ke MQTT broker. Data yang dikirim ke broker tersebut dapat diakuisisi dengan metode subscribe, menggunakan aplikasi MQTT Dashboard. Uji coba sistem dilakukan pengujian waktu respon dengan diberikan panjang data yang berbeda dan jarak yang divariasi, pengujian life time dari node sensor dengan diberika panjang data yang berbeda. Kesimpulan yang didapat yaitu ratarata waktu yang diperlukan oleh node sensor dari akuisisi data sensor hingga disimpan oleh basis data maupun disubscribe oleh pengguna yaitu dua belas detik. Panjang data yang lebih pendek membuat waktu respon dari gateway menjadi lebih cepat dan membuat life time dari node sensor menjadi lebih pendek karena arus yang terukur menjadi lebih besar. Untuk jarak tidak berpengaruh pada sistem yang ditempatkan pada area dan terhubung pada jaringan yang sama.
\end{abstract}

Kata kunci-IoT Gateway, Intel Edison, Protokol MQTT, Node Sensor, Topologi Star

\begin{abstract}
The role of IoT gateway on IoT network is vital, like for strengthen the sensor management. Accordingly, in this research designed an IoT gateway based on MQTT Protocol which implemented in Intel Edison platform and using ten node sensors with star topology.

Results from this research is an IoT gateway system who capable to receive data packet from node sensor, saves the data in database, and publishes the data to MQTT broker. User able to do data acquisition by subscribe method, using MQTT Dasboard application. The system tested by doing the calculation of time response of gateway with variation of data length and variation of distance, life time of node sensor testing by the variation of data length. The conclusions are the time average of from data acquisition by node sensor until gateway saves the data in database and user subscribes the data is twelve seconds. The shorter the data length makes the response time of gateway faster and makes the life time of node sensor shorter because the measured current is bigger. The distance is not gives any impact to the response time of gateway.
\end{abstract}

Keywords—IoT Gateway, Intel Edison, MQTT Protocol, Node Sensor, Star Topology

Received June $25^{\text {th }}, 2018$; Revised April 29 $9^{\text {th }}$,2020; Accepted October $31^{\text {th }}, 2020$ 


\section{PENDAHULUAN}

IoT gateway bertujuan untuk menguatkan manajemen sensor, menjembatani komunikasi antara sensing domain dan network domain, serta membuat jaringan komunikasi menjadi lebih mudah [1]. Interkoneksi antar perangkat pintar tersebut disebut dengan machine to machine communication (M2M) [2]. Komunikasi M2M ataupun IoT banyak diaplikasikan untuk keperluan pemantauan suhu dan kelembaban, kesehatan, maupun pengendalian jarak jauh [3]. Arsitektur dari IoT gateway dapat dibagi menjadi empat buah lapisan, yaitu hardware platform, operating system, services, dan aplikasi.

Peran IoT gateway yang cukup vital dalam jaringan IoT mengharuskan digunakannya platform perangkat keras yang mumpuni. Salah satu platform yang dapat memenuhi kriteria sebagai hardware platform IoT gateway yaitu Intel Edison, yang merupakan sebuah development platform yang diproduksi oleh Intel Corporation dan ditujukan untuk pengembangan IoT maupun produk wearable.

Selain hardware platform yang bagus, juga diperlukan protokol komunikasi yang mumpuni, berukuran ringan, dan mampu memberikan respon dengan cepat. Salah satu protokol yang dapat memenuhi kriteria tersebut yaitu protokol Message Queuing Telemetry Transport (MQTT). Protokol MQTT merupakan sebuah protokol pengiriman pesan dengan berdasarkan client-server publish/subscribe dengan ukuran yang sangat ringan [4]. MQTT terdiri dari tiga komponen, yaitu server, broker, dank klien [5]. Pada jurnal [6] dinyatakan bahwa protokol MQTT beroperasi dengan mengonsumsi energi yang lebih sedikit dibanding dengan protokol HTTP, MQTT mempunyai latensi yang lebih rendah dan lebih dinamis dibanding dengan HTTP, serta server MQTT beroperasi pada lalu lintas data yang lebih rendah, dibanding dengan HTTP yang beroperasi dan mengonsumsi lalu lintas data yang tinggi.

Berdasarkan latar belakang tersebut, dalam penelitian ini akan dirancang dan dibangun IoT gateway berbasis protokol MQTT dengan menggunakan platform Intel Edison, serta melakukan pengamatan pada performa sistem.

\section{METODE PENELITIAN}

\subsection{Analisis Sistem}

Penelitian ini memiliki suatu rancangan sistem IoT gateway yang diharapkan dapat memiliki kemampuan yang handal dalam penerimaan dan penyimpanan paket data yang dikirimkan oleh node sensor, serta mengirim kembali paket data tersebut ke cloud dengan menggunakan protokol MQTT metode publish. Kemudian pengguna bisa mendapatkan data tersebut secara real time dengan menggunakan protokol MQTT metode subscribe.

\subsection{Rancangan Sistem IoT Gateway}

IoT terdiri dari berbagai macam sensor dan perangkat, gateway, jaringan, penyimpanan, serta manajemen monitoring dan analisis [7]. Rancangan sistem ini merupakan rancangan secara keseluruhan yang meliputi rancangan perangkat lunak dan rancangan perangkat keras. Secara garis besar, rancangan sistem pada penelitian ini seperti ditunjukkan pada Gambar 1. Berdasarkan Gambar 1, dapat diketahui bahwa sistem terdiri dari empat bagian, yaitu node sensor, gateway, MQTT broker, dan end user. Node sensor yang dibuat sebanyak sepuluh buah, mencakup sensor DHT11 untuk mendapatkan data suhu dan kelembaban, module RTC DS3231 untuk mendapatkan jam dan tanggal, serta module Wi-Fi ESP8266.

IJEIS Vol. 10, No. 2, October 2020 : 109 - 120 


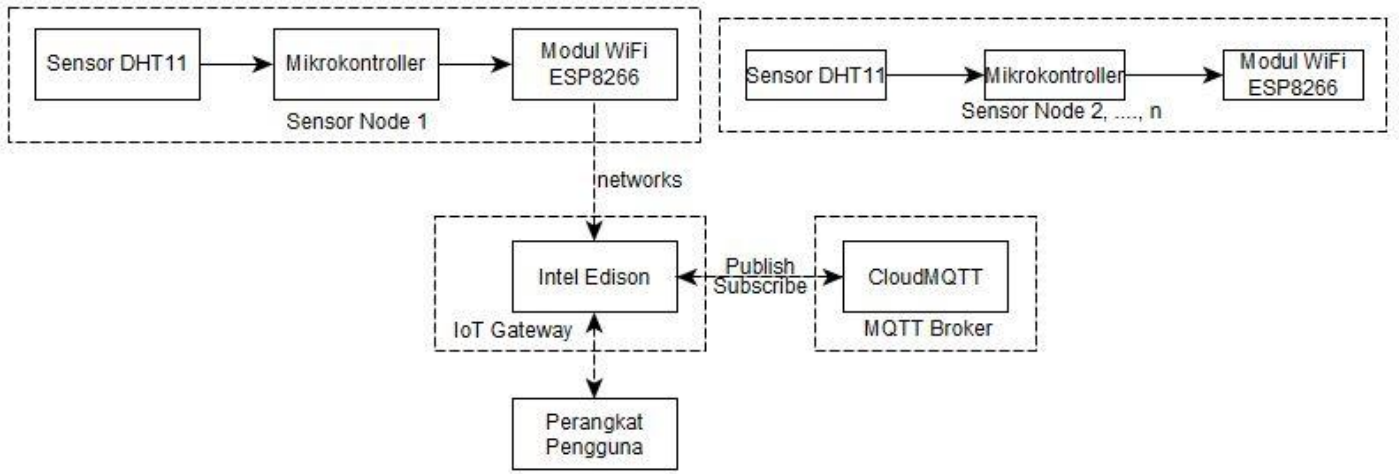

Gambar 1 Diagram Blok Rancangan Sistem

\subsubsection{Rancangan Sistem Perangkat Lunak}

Perangkat lunak yang dimaksud adalah program yang dimasukkan ke dalam mikrokontroler dari node sensor dan ke Intel Edison sebagai gateway. Untuk mikrokontroler, pemrograman dibuat dengan bahasa pemrograman Arduino pada Arduino IDE (Integrated Development Environtment), dan dengan bahasa pemrograman PHP untuk program socket di Intel Edison. Diagram alir untuk program pada node sensor ditunjukkan pada Gambar 2. Setiap node sensor akan mengirimkan paket data yang terdiri dari nomor identitas (1-10), jam dan tanggal, data suhu, dan data kelembaban. Format paket data yang dikirimkan oleh node sensor seperti ditunjukkan oleh Gambar 3. Paket data yang dikirim berukuran 24 bytes dengan tanda '-" sebagai pemisah antar data.

Gambar 4 menunjukkan diagram alir dari IoT gateway pada penelitian ini. Program pada IoT gateway dimulai dari memulai koneksi socket, kemudian node sensor dapat mulai mengirimkan data yang setelah diterima oleh gateway disimpan ke basis data dan mengirimkan data tersebut ke MQTT broker, yang memegang peranan sebagai titik komunikasi utama. MQTT broker mengendalikan pengiriman seluruh data antara pengirim dan yang berhak menerima [8].

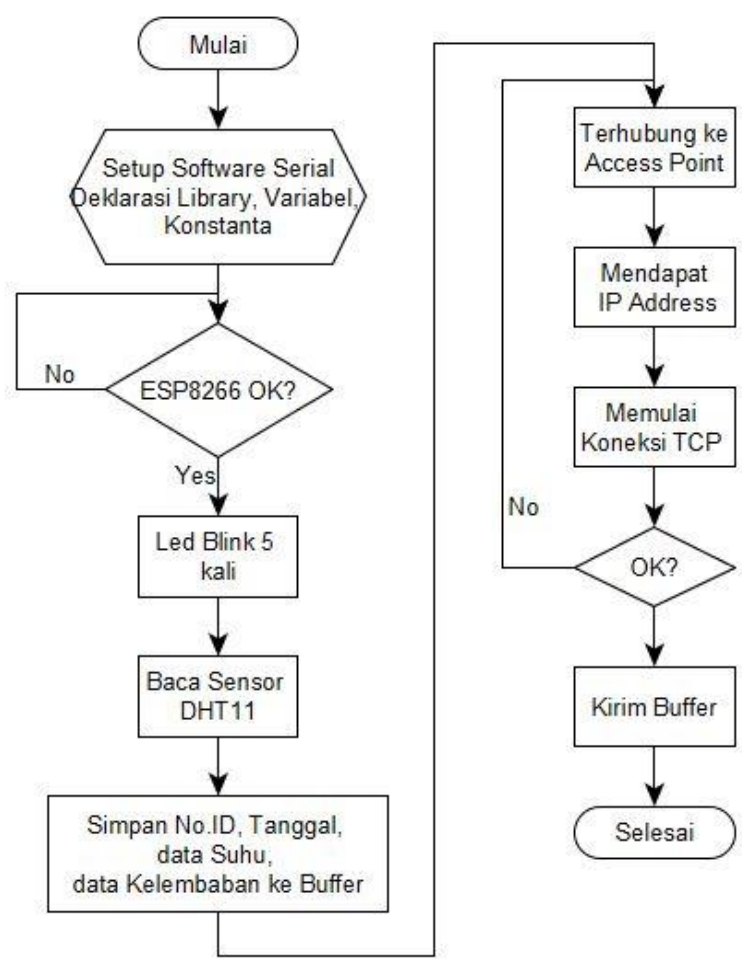

Gambar 2. Diagram Alir Node Sensor 


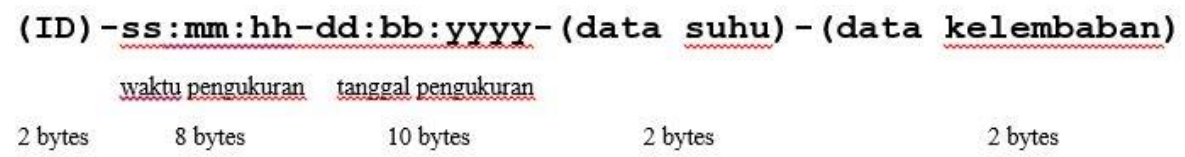

Gambar 3 Format Paket Data

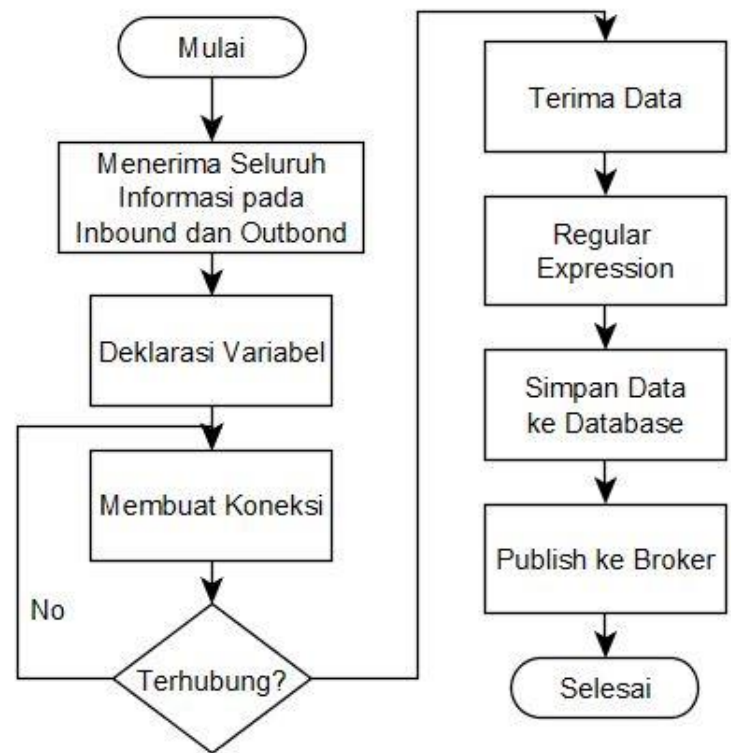

Gambar 3. Diagram Alir IoT Gateway

\subsubsection{Rancangan Sistem Perangkat Keras}

Secara garis besar, rancangan sistem untuk node sensor ditunjukkan pada Gambar 4 . Node sensor terdiri dari Mikrokontroler berupa Arduino Pro Mini, sensor suhu dan kelembaban DHT11, Wi-Fi Module ESP8266, module RTC DS3231, dan power supply beserta regulatornya. Dibutuhkan regulator karena output dari power supply sebesar $5 \mathrm{~V}$, sedangkan node sensor hanya membutuhkan 3,3V.

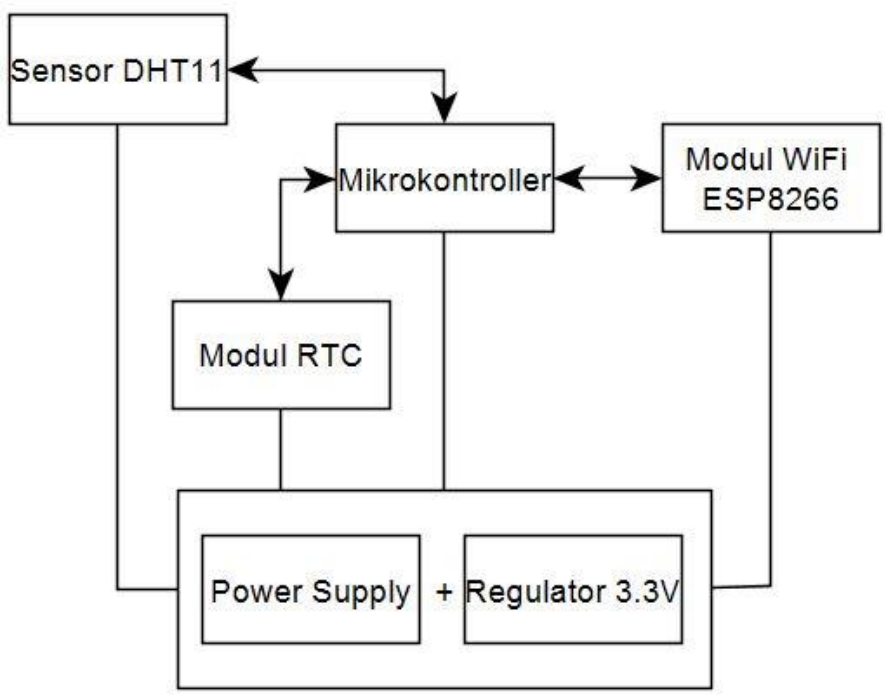

Gambar 4. Arsitektur Node Sensor

IJEIS Vol. 10, No. 2, October 2020 : 109 - 120 
Bila dilihat secara elektronis, node sensor tampak seperti pada Gambar 5. Skematik tersebut menunjukkan jalur rangkaian dari node sensor secara lebih detail, seperti sensor DHT11 terhubung ke digital 2 Mikrokontroller.

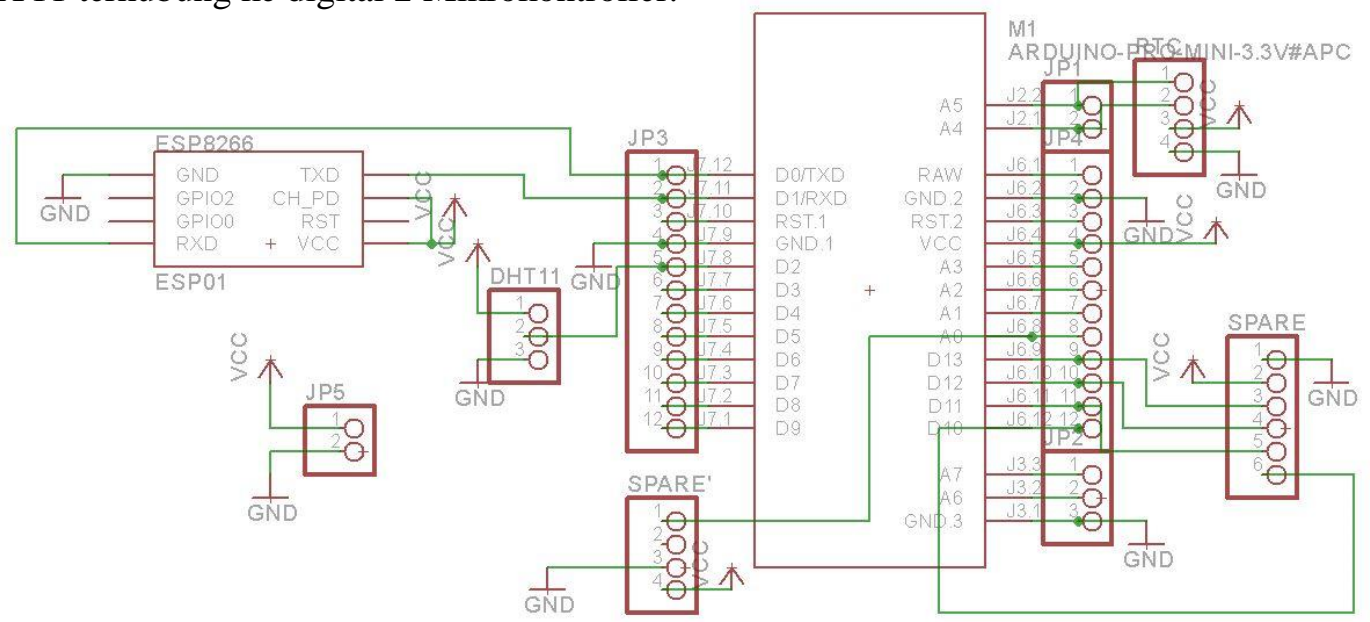

Gambar 5. Skematik Node Sensor

\subsection{Topologi Pengujian Node Sensor}

Dalam mengirimkan paket data, topologi dari node sensor yang digunakan yaitu topologi star, dimana setiap node sensor langsung mengirimkan data ke gateway tanpa perlu mengetahui informasi mengenai node tetangga. Kelebihan dari topologi star yaitu, jika terdapat salah satu koneksi dari node sensor yang terputus, tidak akan berpengaruh pada node sensor lainnya [9]. Topologi star pada penelitian ini seperti ditunjukkan pada Gambar 6. Setiap node sensor diletakkan sejauh satu meter dari gateway.

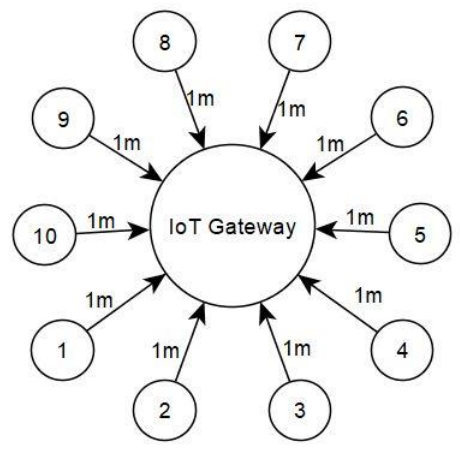

Gambar 6. Topologi Node Sensor

\section{HASIL DAN PEMBAHASAN}

Pada penelitian ini terdapat empat cara pengujian life time dari node sensor, response time, dan performa dari gateway, yaitu dengan diberikan panjang data tetap dan jarak sensor node ke gateway tetap, variasi panjang data dan jarak tetap, panjang data tetap dan variasi jarak, serta variasi panjang data dan variasi jarak.

\subsection{Panjang Data Tetap dan Jarak Tetap}

Pengujian pertama dilakukan dengan diberikan panjang data yang tetap, sesuai dengan Gambar 3 dan jarak antara sensor node dengan gateway yang juga tetap, yaitu sepanjang satu 
meter. Pengujian pertama ini ditujukan sebagai pembanding pengujian kedua hingga pengujian keempat.

\subsubsection{Pengujian Life Time Node Sensor}

Untuk Jaringan Sensor Nirkabel, efisiensi energi merupakan salah satu fungsional yang penting, karena secara langsung mempengaruhi siklus hidup dari sistem [10]. Dalam penelitian ini, setiap node sensor diukur besar arus yang terpakai untuk mengetahui seberapa lama sebuah sensor node dapat bertahan menyala dan terus megirimkan data sensor ke gateway. Cara yang digunakan untuk menghitung life time dari sensor node yaitu dengan membagi kapasitas baterai yang dipakai pada setiap node dengan arus yang terukur pada Amperemeter. Satuan kapasitas baterai yang digunakan adalah miliAmpere hour (mAh), sedangkan satuan arus yang digunakan yaitu miliAmpere, sehingga akan didapatkan life time dari sensor node dalam satuan jam. Pengujian dilakukan dengan menggunakan Amperemeter dan dihitung secara rangkaian seri.

Hasil pengujian untuk pengujian life time dengan panjang data berukuran 24 bytes dapat dilihat pada Tabel 1. Terdapat perbedaan besar nilai arus yang terukur pada masing-masing sensor node. Sensor node dengan nilai arus tertinggi yaitu nomor 9, sebesar 143,6 mA, dan yang terendah yaitu sensor nomor 1 sebesar 104.4 mA. Dengan kapasitas baterai yang sama, yakni $3200 \mathrm{mAh}$, bentuk rangkaian yang sama, dan jenis komponen yang sama bisa menghasilkan perbedaan nilai arus terukur pada masing-masing rangkaian sensor node. Hipotesis yang diambil terhadap perbedaan nilai arus yang terukur pada masing-masing sensor node adalah adanya perbedaan nilai hambatan total pada masing-masing rangkaian sensor node. Perbedaan nilai hambatan total tersebut bisa dipengaruhi oleh perbedaan kualitas jalur konduktif pada PCB maupun kualitas penyolderan komponen. Selain itu, perbedaan nilai arus yang terukur pada masing-masing sensor node dipengaruhi oleh panjang data yang diolah dan dikirim ke gateway.

Dengan membagi besar kapasitas baterai yang digunakan dengan nilai arus yang terukur, didapatkan waktu nyala / lifetime dari setiap sensor node. Semakin kecil arus yang terukur pada rangkaian, maka waktu nyalanya akan semakin panjang, demikian juga sebaliknya, bila arus yang terukur pada rangkaian semakin besar, maka waktu nyalanya akan semakin pendek. Berdasarkan Tabel 1 dapat diketahui bahwa sensor node dengan waktu nyala yang paling panjang yaitu nomor 1, yakni selama 30,6 jam dan yang paling pendek yaitu sensor node nomor 9 selama 22,3 jam.

Dengan nilai rata-rata arus yang terukur untuk sepuluh sensor node tersebut $125,9 \mathrm{~mA}$, didapatkan data bahwa jaringan sensor node tersebut secara efektif mampu melakukan pengukuran data suhu dan kelembaban serta melakukan pengiriman data selama 25,7 jam.

Kesimpulan dari pengujian pengukuran arus dan lifetime sepuluh sensor node ini yaitu perbedaan besar nilai hambatan pada masing-masing rangkaian sensor node menyebabkan adanya perbedaan nilai arus yang terukur dan waktu nyala.

Tabel 1 Hasil Pengujian Life Time Node Sensor

\begin{tabular}{|c|c|c|c|}
\hline Node & Kapasitas Baterai $(\mathrm{mAh})$ & Arus Terukur $(\mathrm{mA})$ & Lifetime (jam) \\
\hline 1 & 3200 & 104.4 & 30.6 \\
\hline 2 & 3200 & 133.2 & 24.0 \\
\hline 3 & 3200 & 135.9 & 23.5 \\
\hline 4 & 3200 & 137.8 & 23.2 \\
\hline 5 & 3200 & 122.3 & 26.2 \\
\hline 6 & 3200 & 117.8 & 27.2 \\
\hline 7 & 3200 & 139.8 & 22.9 \\
\hline 8 & 3200 & 118.5 & 27.0 \\
\hline 9 & 3200 & 143.6 & 22.3 \\
\hline 10 & 3200 & 106.0 & 30.2 \\
\hline Rata-Rata & 3200 & 125.9 & 25.7 \\
\hline
\end{tabular}

IJEIS Vol. 10, No. 2, October 2020 : $109-120$ 


\subsubsection{Pengujian Response Time Gateway}

Pengujian waktu respon dilakukan agar dapat diperkirakan seberapa banyak data yang dapat diakuisisi dalam rentang waktu tertentu. Pengujian ini dilakukan dengan menghitung selisih waktu dari penerimaan satu data dengan waktu penerimaan data berikutnya yang disimpan di basis data gateway.

Masing-masing data sensor node diambil sebanyak seratus data dan dihitung rata-rata waktu respons tersebut, sehingga kemudian diketahui berapa lama waktu respon dari setiap akuisisi data hingga disimpan di basis data.

Tabel 2 Hasil Pengujian Waktu Respon Gateway

\begin{tabular}{|c|c|c|}
\hline Node & Jarak $(\mathrm{m})$ & Waktu Respons (detik) \\
\hline 1 & 1 & 12,12 \\
\hline 2 & 1 & 12,12 \\
\hline 3 & 1 & 12,12 \\
\hline 4 & 1 & 12,32 \\
\hline 5 & 1 & 12,14 \\
\hline 6 & 1 & 12,14 \\
\hline 7 & 1 & 12,14 \\
\hline 8 & 1 & 12,10 \\
\hline 9 & 1 & 12,08 \\
\hline 10 & 1 & 12,10 \\
\hline
\end{tabular}

Mengacu pada tabel 2, rata-rata waktu respon setiap node dari akuisis data sensor hingga disimpan ke basis data gateway adalah 12 detik. Bila diasumsikan tidak adanya gangguan, baik pada sensor node, jaringan, maupun gateway, dalam setiap satu jam, bisa didapatkan data akuisisi sensor sebanyak tiga ratus data. Dengan rata-rata lifetime selama 25,7 jam, maka bisa diasumsikan bahwa dalam satu lifetime sensor node, gateway dapat menerima dan menyimpan data sensor sebanyak 7710 data untuk satu sensor node. Namun, tentunya perlu dipastikan bahwa sensor node yang diterapkan telah dirancang dengan baik, dan jaringan yang digunakan tidak terganggu.

Dari pengujian ini, dapat disimpulkan bahwa rata-rata waktu respon dari akuisisi data sensor node selama 12 detik, sehingga bisa mendapatkan data yang cukup banyak dalam satu kali lifetime.

\subsection{Variasi Panjang Data dan Jarak Tetap}

Pengujian kedua dilakukan dengan diberikan panjang data yang lebih pendek dibanding dengan pengujian pertama dan diberikan jarak antara sensor node dengan gateway yang juga tetap, yaitu sepanjang satu meter.

Format paket data untuk pengujian kedua ditunjukkan pada gambar 7 berikut ini.

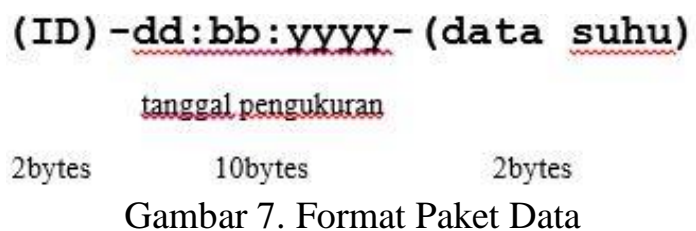

Format paket data pada pengujian kedua, berbeda dengan format paket data yang digunakan pada pengujian pertama, yaitu dengan tidak dikirimkannya data waktu pengukuran dan data kelembaban. Dengan mengurangi data waktu pengukuran dan data kelembaban, ukuran paket data menjadi 14 bytes, dibanding 24 bytes pada pengujian yang pertama. 


\subsubsection{Pengujian Life Time Baterai}

Dalam menguji seberapa lama sebuah node sensor dapat bertahan, digunakan Amperemeter untuk mengukur arus yang mengalir pada rangkaian sensor node, dan diukur secara seri. Data pada Tabel 3 merupakan hasil pengukuran arus sensor node untuk pengujian kedua.

Tabel 3 Hasil Pengukuran Lifetime Setiap Node Sensor

\begin{tabular}{|c|c|c|c|}
\hline Node & Kapasitas Baterai $(\mathrm{mAh})$ & Arus Terukur $(\mathrm{mA})$ & Lifetime (jam) \\
\hline 1 & 3200 & 146.3 & 21.9 \\
\hline 2 & 3200 & 118.1 & 27.1 \\
\hline 3 & 3200 & 143.3 & 22.3 \\
\hline 4 & 3200 & 104.4 & 30.6 \\
\hline 5 & 3200 & 143.6 & 22.3 \\
\hline 6 & 3200 & 142.9 & 22.4 \\
\hline 7 & 3200 & 109.5 & 29.2 \\
\hline 8 & 3200 & 143.8 & 22.2 \\
\hline 9 & 3200 & 133.9 & 23.8 \\
\hline 10 & 3200 & 141.6 & 22.5 \\
\hline Rata-Rata & 3200 & 132.7 & 24.4 \\
\hline
\end{tabular}

Mengacu pada Tabel 3, terdapat perbedaan besar nilai arus yang terukur pada masingmasing sensor node. Sensor node dengan nilai arus tertinggi yaitu nomor 1, sebesar 146,3 mA, dan yang terendah yaitu sensor nomor 4 sebesar $104.4 \mathrm{~mA}$. Dengan kapasitas baterai yang sama, yakni $3200 \mathrm{mAh}$, bentuk rangkaian yang sama, dan jenis komponen yang sama bisa menghasilkan perbedaan nilai arus terukur pada masing-masing rangkaian sensor node.

Dengan diberikan panjang data yang berbeda, didapatkan pula besar arus yang berbeda. Dengan melihat hasil keseluruhan sensor node, diketahui bahwa panjang data yang lebih pendek membuat arus yang terukur pada sensor node menjadi lebih besar, dibandingkan dengan pengujian pertama. Dengan semakin besarnya arus yang terukur, didapatkan lifetime yang semakin pendek. Berdasarkan hasil penelitian tersebut, didapatkan bahwa lifetime rata-rata dari sepuluh sensor node tersebut selama 24,4 jam, lebih pendek dibanding dengan pengujian pertama yang menggunakan panjang data lebih besar, yaitu selama 25,7 jam.

Kesimpulan dari pengujian pengukuran arus dan lifetime sepuluh sensor node ini yaitu panjang data yang diolah dan dikirimkan oleh sensor node dapat mempengaruhi lama lifetime dari sensor node tersebut.

\subsubsection{Pengujian Response Time Gateway}

Pada metode pengujian kedua, dilakukan pengujian waktu respon dari akuisisi data hingga diterima gateway dengan diberikan panjang data seperti pada Gambar 3 dan dilakukan selama masing-masing sepuluh menit. Pengujian ini bertujuan untuk mengetahui pengaruh panjang data pada waktu respon penerimaan data oleh gateway dibandingkan dengan hasil pengujian pertama. Hasil data pengujian ditunjukkan pada Tabel 4 berikut ini.

Tabel 4 Hasil Pengujian Waktu Respon

\begin{tabular}{|c|c|c|}
\hline Node & Jarak $(\mathrm{m})$ & Waktu Respons (detik) \\
\hline 1 & 1 & 11,90 \\
\hline 2 & 1 & 11,90 \\
\hline 3 & 1 & 11,90 \\
\hline 4 & 1 & 11,90 \\
\hline 5 & 1 & 12,00 \\
\hline 6 & 1 & 12,00 \\
\hline 7 & 1 & 12,10 \\
\hline 8 & 1 & 12,00 \\
\hline 9 & 1 & 12,00 \\
\hline 10 & 1 & 11,90 \\
\hline
\end{tabular}

IJEIS Vol. 10, No. 2, October 2020 : 109 - 120 
Berdasarkan Tabel 4, didapatkan hasil pengujian waktu respon yang relatif lebih cepat dibandingkan dengan pengujian pertama. Hipotesis yang diambil yaitu bahwa semakin pendek data yang dikirim, maka waktu yang dibutuhkan untuk mengolah data dan mengirimkan data semakin cepat.

\subsection{Panjang Data Tetap dan Variasi Jarak}

\subsubsection{Pengujian Response Time Gateway}

Pengujian ketiga dilakukan dengan memberikan panjang data yang sama dengan pengujian pertama, yaitu berukuran 24 bytes, dan diberikan variasi jarak, dari satu meter, setengah meter, dan sepuluh centimeter. Pengujian ini bertujuan untuk mengetahui pengaruh jarak terhadap waktu respon dari gateway terhadap data yang dikirim oleh node sensor.

Tabel 5 Waktu Respon Pada Jarak 50 cm

\begin{tabular}{|c|c|c|}
\hline Node & Jarak $(\mathrm{cm})$ & Waktu Respon (detik) \\
\hline 1 & 50 & 12,15 \\
\hline 2 & 50 & 12,11 \\
\hline 3 & 50 & 12,13 \\
\hline 4 & 50 & 12,22 \\
\hline 5 & 50 & 12,14 \\
\hline 6 & 50 & 12,16 \\
\hline 7 & 50 & 12,17 \\
\hline 8 & 50 & 12,13 \\
\hline 9 & 50 & 12,10 \\
\hline 10 & 50 & 12,15 \\
\hline \multicolumn{2}{|c|}{ Rata-Rata } \\
\hline
\end{tabular}

Tabel 6 Waktu Respon Pada Jarak $10 \mathrm{~cm}$

\begin{tabular}{|c|c|c|}
\hline Node & Jarak $(\mathrm{cm})$ & Waktu Respon (detik) \\
\hline 1 & 10 & 12,12 \\
\hline 2 & 10 & 12,14 \\
\hline 3 & 10 & 12,11 \\
\hline 4 & 10 & 12,16 \\
\hline 5 & 10 & 12,17 \\
\hline 6 & 10 & 12,13 \\
\hline 7 & 10 & 12,12 \\
\hline 8 & 10 & 12,10 \\
\hline 9 & 10 & 12,11 \\
\hline 10 & 10 & 12,14 \\
\hline \multicolumn{2}{|c|}{ Rata-Rata } & 12.13 \\
\hline
\end{tabular}

Berdasarkan Tabel 5 dan Tabel 6, diketahui bahwa waktu respon dari gateway dengan jarak antara node sensor dengan gateway sepanjang satu meter, setengah meter, dan sepuluh centimeter relatif tidak berbeda. Hipotesis yang diambil yaitu jarak antara node sensor dengan gateway yang keduanya terhubung ke access point tidak berpengaruh pada waktu respon.

\subsection{Variasi Panjang Data dan Variasi Jarak}

Pengujian yang keempat yaitu dengan diberikan panjang data seperti pada gambar 7 dan diberikan variasi jarak seperti pada pengujian ketiga. Sama seperti pengujian ketiga, pengujian keempat juga lebih ditujukan untuk mengetahui waktu respon dari akuisisi data oleh node sensor hingga diterima oleh gateway. 


\subsubsection{Pengujian Waktu Respon Gateway}

Data hasil pengujian waktu respon dari akuisisi data oleh node sensor hingga disimpan di basis data gateway ditunjukkan pada Tabel 7.

Tabel 7 Data Pengujian Waktu Respon

\begin{tabular}{|c|c|c|}
\hline Node & Jarak $(\mathrm{cm})$ & Waktu Respon (detik) \\
\hline 1 & 50 & 11,92 \\
\hline 2 & 50 & 11,91 \\
\hline 3 & 50 & 11,92 \\
\hline 4 & 50 & 11,92 \\
\hline 5 & 50 & 12,03 \\
\hline 6 & 50 & 12,01 \\
\hline 7 & 50 & 12,09 \\
\hline 8 & 50 & 12,08 \\
\hline 9 & 50 & 12,01 \\
\hline 10 & 50 & 11,91 \\
\hline
\end{tabular}

Table 8 Data Pengujian Waktu Respon

\begin{tabular}{|c|c|c|}
\hline Node & Jarak $(\mathrm{cm})$ & Waktu Respon (detik) \\
\hline 1 & 10 & 11,92 \\
\hline 2 & 10 & 11,91 \\
\hline 3 & 10 & 11,92 \\
\hline 4 & 10 & 11,92 \\
\hline 5 & 10 & 12,03 \\
\hline 6 & 10 & 12,01 \\
\hline 7 & 10 & 12,09 \\
\hline 8 & 10 & 12,08 \\
\hline 9 & 10 & 12,01 \\
\hline 10 & 10 & 11,91 \\
\hline
\end{tabular}

Berdasarkan Tabel 7 dan Tabel 8, data yang didapatkan relatif sama dengan data pengujian kedua. Hipotesis yang diambil sama seperti pengujian ketiga, yaitu jarak antara node sensor dengan gateway yang keduanya terhubung ke access point yang sama tidak berpengaruh pada waktu respon.

\subsection{Hasil Akuisisi Data Dari MQTT Broker}

Dalam mengakuisisi data dari node sensor dengan menggunakan protokol MQTT, digunakan metode subscribe. Pada penelitian ini, digunakan aplikasi Android "MQTT Dashboard" untuk melakukan pengamatan maupun akuisisi data. MQTT Dashboard merupakan aplikasi mobile yang bekerja pada smart phone Android, yang dapat digunakan untuk pengamatan data yang dikirim dari node sensor maupun gateway melalui protokol MQTT, dengan menyediakan representasi data secara grafis [11]. Gambar 8 merupakan salah satu contoh dari hasil subscribe data node sensor yang telah dikirim oleh gateway ke MQTT broker.

IJEIS Vol. 10, No. 2, October 2020 : 109 - 120 


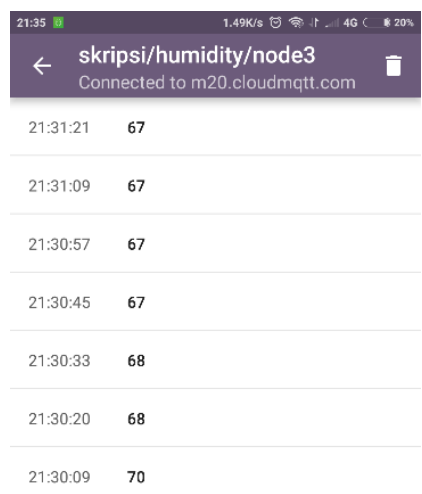

Gambar 8 Hasil Subscribe Data Node Sensor

Berdasarkan Gambar 8, dapat dilihat bahwa data dapat disubscribe dalam waktu dua belas detik sekali. Artinya, rata-rata dalam satu menit didapatkan data sebanyak lima kali. Hipotesis yang dapat diambil yaitu bahwa MQTT merupakan protokol yang ringan dan cepat dalam pemrosesannya, sehingga sesuai untuk diimplementasikan dalam sistem WSN dengan karakteristik low power.

\section{KESIMPULAN}

Berdasarkan penelitian yang dilakukan, telah dapat dirancang dan dibangun sebuah sistem IoT Gateway menggunakan platform Intel Edison berbasis protokol MQTT.

Kesimpulan yang pertama yaitu panjang data yang dikirim berpengaruh terhadap waktu komputasi node sensor, semakin pendek data yang dikirim, maka semakin cepat waktu respon dari gateway.

Kesimpulan kedua yaitu panjang data berpengaruh juga terhadap lifetime dari node sensor. Semakin pendek data yang diolah, maka arus yang terukur akan semakin besar. Arus yang semakin besar membuat lifetime dari node sensor semakin pendek.

Kesimpulan ketiga yaitu jarak tidak berpengaruh pada waktu respon, ketika keduanya terhubung pada access point yang sama.

Kesimpulan keempat yaitu MQTT merupakan protokol komunikasi antara client dengan server yang berukuran ringan dan cepat dalam pemrosesannya, sehingga sesuai untuk diimplementasikan dalam WSN dengan karakteristik low power.

\section{SARAN}

Saran yang dapat dilakukan untuk pengembangan dalam penelitian selanjutnya yaitu, penggunaan sensor yang lebih banyak, guna menguji performa sistem IoT Gateway dengan data yang semakin kompleks.

\section{UCAPAN TERIMA KASIH}

Penulis mengucapkan terima kasih kepada semua pihak yang telah membantu dalam Mengerjakan penelitian ini. 


\section{DAFTAR PUSTAKA}

[1] Q. Zhu, R. Wang, Q. Chen, Y. Liu, and W. Qin, "IOT Gateway : Bridging Wireless Sensor Networks into Internet of Things,"IEEE/IFIP International Conference on Embedded and Ubiquitous Computing, 2010 [Online]. Available: https://ieeexplore.ieee.org/document/5703542/. [Accessed: 5-Aug-2016]

[2] S. K. Datta, C. Bonnet, and N. Nikaein, "An IoT Gateway Centric Architecture to Provide Novel M2M Services,"IEEE WF-IoT (World Forum on Internet of Things), 2014 [Online]. Available: https://ieeexplore.ieee.org/document/6803221. [Accessed: 5Aug-2016]

[3] D. Pradana, and B. A. A. Sumbodo, "Rancang Bangun M2M (Machine to Machine) Communication Berbasis 6LoWPAN,"IJEIS (Indonesian J. Electron. Instrum. Syst.), 2017 [Online]. Available: https://jurnal.ugm.ac.id/ijeis/article/view/18087/16016. [Accessed: 12-Aug-2017]

[4] B. S. Ullas, S. Anush, J. Roopa, and G. Raju, "Machine to Machine Communication for Smart Systems using MQTT,"IJAREEIE (International J. Advan. Res. Electric., Electron., Instrum., Engine.), vol. 3, no. 3, Mar. 2014 [Online]. Available: www.ijareeie.com/upload/2014/march/67_Machine.pdf. [Accessed: 18-Jul-2016]

[5] M. Anush, S. Babu, S. M. Reddy, V. Krishna, and B. Bhagyasree, "Performance Analysis of Data Protocols of Internet of Things: A Qualitative Review,"IJPAM (International J. Pure Appl. Math.), vol. 115, no. 6, 2017 [Online]. Available: https://acadpubl.eu/jsi/2017-115-6-7/articles/6/6.pdf. [Accessed: 12-Aug-2017]

[6] B. S. S. Tejesh, and S. Neeraja, "Implementation of an Efficient Smart Home System using MQTT,'IRJET (International Res. J. Engine. Tech.), vol. 4, no. 3, Mar. 2017 [Online]. Available: https://irjet.net/archives/V4/i3/IRJET-V4I3505.pdf. [Accessed: 12Aug-2017]

[7] W. G. Soliman, and D. V. R. Reddy,"A Review: Internet-Of-Things Gateways Architectures And Challenges,"IJACEN (International J. Advan. Comput. Engine. Network.), vol. 5, no. 10, Oct. 2017 [Online]. Available: http://www.iraj.in/journal/journal_file/journal_pdf/3-409-151445891340-45.pdf. [Accessed: 1-Sep-2016]

[8] A. Priyadharshini, S. Vanarasan, and N. Vijayakumar, “An Intelligent Patient Monitoring Through IoT By MQTT,’IJCSE (International J. Compute. Scien. Engine.), Apr. $2017 \quad$ [Online]. Available: http://www.internationaljournalssrg.org/IJCSE/2017/Special-Issues/2ICEIS/IJCSE2ICEIS-P104.pdf. [Accessed: 12-Aug-2017]

[9] A. Anjum, S. A. Pasha, "A Brief of Computer Network Topology for Data Communication and Networking,"IJETT (International J. Engine. Trends Tech.), Vol. 22, no. 7, Apr. 2015 [Online]. Available: http://www.ijettjournal.org/2015/volume22/number-7/IJETT-V22P267.pdf. [Accessed: 12-Aug-2017]

[10] R. Piyare, and S. Lee,"Performance Analysis of XBee ZB Module Based Wireless Sensor Networks," IJSER (International J. Scien. Engine. Res.), vol. 4, no. 4, Apr. 2013 [Online]. Available: www.rajeevpiyare.com/wp-content/uploads/2016/12/PerformanceAnalysis-of-XBee-ZB-Module-Based-Wireless-Sensor-Networks1.pdf. [Accessed: 26May-2018]

[11] P. G. Krishna, K. S. Ravi, V. S. S. S. Kumar, and M. V. S. N. S. Kumar, "Implementation of MQTT Protocol On Low Resourced Embedded Network,"IJPAM (International J. Pure Appl. Math.), vol. 116, no. 6, 2017 [Online]. Available: https://acadpubl.eu/jsi/2017-116-5-7/articles/6/27.pdf. [Accessed: 12-Aug-2017]

IJEIS Vol. 10, No. 2, October 2020 : 109 - 120 